\title{
The Economic Value of Common Urban Trees in the State of Qatar from an Air Quality Control Perspective
}

\author{
Rima J. Isaifan ${ }^{1,2, *}$, Hanadi Al-Thani², Mohammed Ayoub¹, Brahim Aïssa ${ }^{1,2}$, Muammer Koc ${ }^{2}$ \\ ${ }^{1}$ Qatar Environment and Energy Research Institute, Hamad Bin Khalifa University, Qatar Foundation, P.O. Box 5825, Doha, Qatar. \\ ${ }^{2}$ Division of Sustainable Development (DSD), Hamad Bin Khalifa University (HBKU) / Qatar Foundation (QF), Education City, P.0. Box 5825, Doha, Qatar.
}

\section{ART ICLE DETAILS}

Article history:

Received 22 June 2018

Accepted 29 June 2018

Available online 14 July 2018

\section{Keywords:}

Air Quality

Urban Trees

Economic Assessment

Urban Planning

Gaseous Pollutants

Particulate Matter

\begin{abstract}
A B S T RAC T
Increasing urbanization brings about several sustainability challenges for its citizens. Among many, air quality is probably the most important and common one due to limitation in natural sources and the increased use of energy in buildings and transportation. Many cities have considered including urban vegetation in their sustainable development plans to abate the effects of climate change as well as for beautification of neighborhoods to motivate positive behavior of their citizens. Trees have been known for cleaning air by converting carbon dioxide into oxygen reducing their impact on health and materials. Moreover, trees can directly affect particulate matter concentration by (1) removing particles, (2) emitting particles or (3) by the re-suspension of particles on the plant surface. This study presents the air quality impacts of urban vegetation in the city of Doha (State of Qatar) under arid conditions, which can be mainly described with high temperature, high relative humidity and high concentration of particulate matters originating from multiple sources. Three abundant local urban tree species were selected for this study, namely Acacia (Wattles), Ziziphus (Sidra) and Phoenix dactylifera (palm date) trees. Their environmental economic value (EEV) was evaluated and compared based on their capability to abate gaseous and particulate pollutants utilizing the application of the National Tree Benefit Calculator. To this end, Acacia was found to have the highest EEV under Doha city's weather conditions.
\end{abstract}

\section{Introduction}

Urban vegetation has been reported to have several ecosystem services such as providing scenic public landscape, reducing impacts of flooding, reduction in the use of fossil fuels for heating and cooling in addition to several positive effects on air quality through filtration of airborne particulate matter $[1,2]$. Urban planning is one of the critical fields that accounts for the dynamic changes in cities around the world, especially with shrinking areas due to urbanizations [3]. Hence, many countries are considering urban vegetation in their current and future plans for their role to mitigate adverse climate change impacts such as global warming, rise in sea level, in addition to the beautification of neighborhoods to motivate positive behavior of their citizens [4]. Trees are known for cleaning air by converting carbon dioxide into oxygen reducing their impact on health and materials [5]. On the other hand, mitigation of dust in desert areas is of critical importance to reduce their effect on solar panels $[6,7]$. In urban places, trees can directly affect particulate matter (PM) concentration in the air by several routes: (1) by removing particles, (2) emitting particles or (3) by the re-suspension of particles on the surface of these trees $[8,9]$. Trees can also lead to PM formation by emitting volatile organic compounds, which act as precursor for PM secondary formation [8]. On the other hand, PM deposition on tree leaves adversely affect the health of trees. These particles, which deposit on the leaves can block light and hence affect photosynthesis process or can be absorbed by the tree if the particles are tiny enough.

Maher et al. [10] reported recently that silver birch trees can absorb as much as $50 \%$ of the PM generated by vehicles in their study that was conducted out for a city block in Lancaster city in The United Kingdom. First, the PM content was determined based on dust samples taken from homes participating in the experiment to evaluate the original amount of PM to which the families are exposed. After initial samples were analyzed, the streets were then lined with 24 young silver birch trees planted in tubs along the pavement in front of four of the participant homes, effectively creating a barrier between them and the streets where heavy

transportation takes place. After two weeks of starting the experiment, the researchers found that the homes that had birch tree screen planted in their front achieved more than 50\% decrease in PM concentration compared to the homes that did not. This was followed by another step to investigate how the trees were able to filter out or remove PM so efficiently. Hence, the authors studied silver birch tree leaves with a scanning electron microscope (SEM), from which they concluded clearly that tiny hair-like structures on the surface of those leaves were responsible for removing the particulates from the air.

The effect of leaf surface structure on the efficiency of trees to capture PM have been also reported recently by Chen and coworkers [11]. In their study, they investigated the foliar characteristics for effective $\mathrm{PM}_{2.5}$ capture and presented differences in foliar $\mathrm{PM}_{2.5}$ recapture capacity between one tree species to another following a rain event. The foliage is another word for the leaves of the plant which acts as a bio-filter of air pollution and improves air quality due to the leaves' rough texture and large contact. The researchers hence concluded that the conifer needle shaped-leaves are more efficient than broadleaved species for $\mathrm{PM}_{2.5}$ accumulation and capture after rain. Furthermore, the amount of $\mathrm{PM}_{2.5}$ removal by rainfall was determined by the total foliar $\mathrm{PM}_{2.5}$. They have reported that not all $\mathrm{PM}_{2.5}$ remained on the foliage (leaves), but also $\mathrm{PM}_{2.5}$ was re-suspended during the growing season, and thus reduced the net particular accumulation in some species [11].

Trees are not only efficient for PM abatement, but they are also efficient for providing various ecosystem services in urban context such as the regulation of temperature, carbon dioxide sequestration and removal of other gaseous pollutants [12-14]. Nowak [8] reported that trees in New York City removed a total mass of about 1,821 metric tons of air pollution in 1994. This has reflected at an estimated value of $\$ 9.5$ million benefit to society. The study involved other cities in the United States as well, and the different rate of pollution removal by tries from one city to another was dependent on the total amount of air pollution, length of in-leaf season, precipitation, and other meteorological variables. It was found that large healthy trees which have diameter greater than $77 \mathrm{~cm}$ remove approximately 70 times more air pollution annually $(1.4 \mathrm{~kg} / \mathrm{yr})$ than small healthy trees with less than $8 \mathrm{~cm}$ in diameter $(0.02 \mathrm{~kg} / \mathrm{yr})[8]$.

In this work, we evaluate for the first time in Doha/Qatar the air quality impact and environmental economic value of three abundant urban trees: 
Acacia (Wattles), Ziziphus (Sidra) and Phoenix dactylifera (palm date). The environmental economic value of each tree was estimated based on its capability to abate gaseous and particulate pollutants utilizing the application of the National Tree Benefit Calculator (NTBC).

\section{Experimental Methods}

In order to evaluate the environmental economic benefits of the three abundant urban trees in Doha city, the National Tree Benefit Calculator was used (NTBC). The NTBC is a tool developed by Casey Tree and Davey Tree Expert Co. free for public use to make a direct estimation of the benefits of individual trees. To use this tool, four pieces of input data should be selected:

- the location of the area

- the tree species name,

- a tree diameter value that ranges between 0 and 45 inches; and

- type of land use where the tree is planted.

Therefore, to start using the tool, a specific location in the United States should be first selected since this tool was developed mainly for use within USA boundaries. Hence, we selected Southern California desert since it has the same climate zone as Qatar (Fig. 1) based on the six principal groups of world climates (Polar, Temperate, Arid, Tropical, Mediterranean and Mountains) [2].

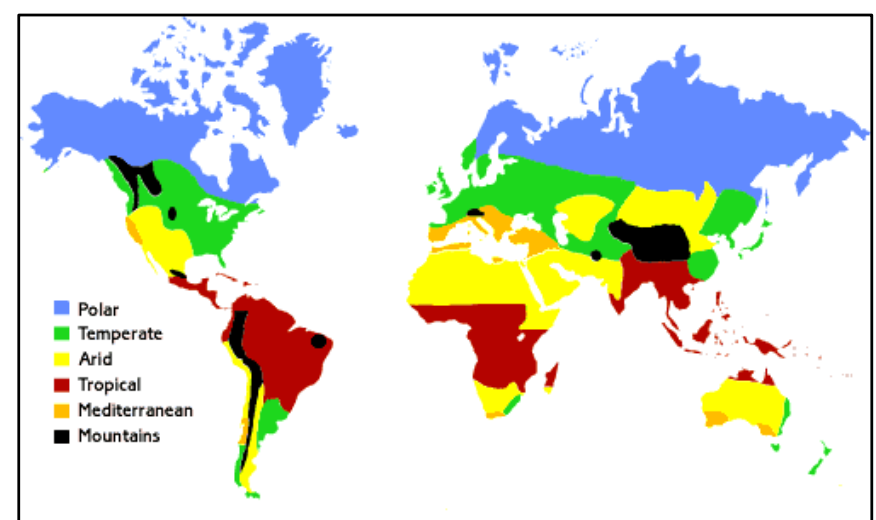

Fig. 1 World Climate Zones showing that Qatar has the same climate zone as of the desert in Southern California [15]

Second, a species name should be selected. The three trees investigated in this study are Acacia (Wattles), Ziziphus (Sidra) and Phoenix dactylifera (palm date) Trees (Fig. 2), which are considered some of the most abundant species that grow in urban environment in Doha city [16] (Environmental Studies Center [17]).
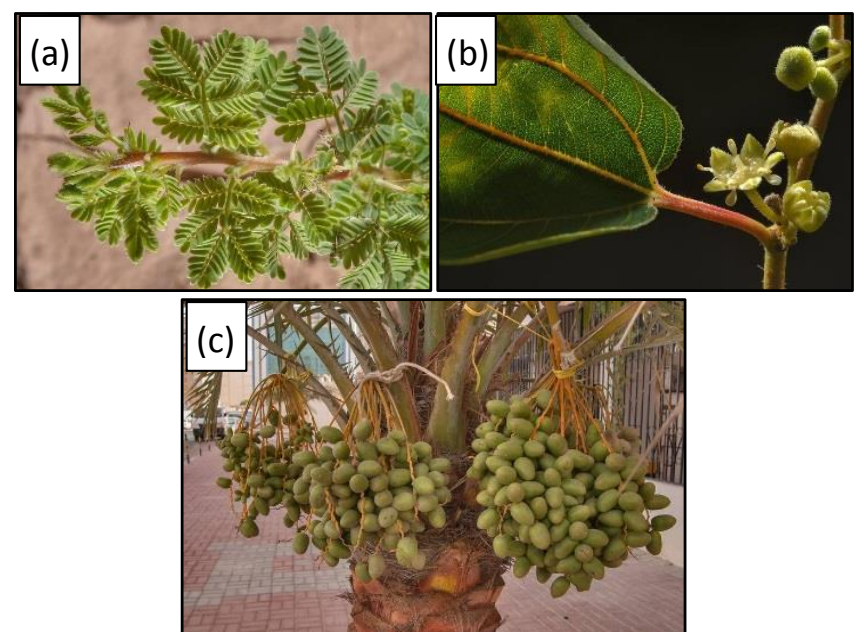

Fig. 2 Photos of (a) Acacia (Wattles), (b) Ziziphus (Sidra) and (c) Phoenix dactylifera (palm date), some of the most abundant species that grow in urban environment in Doha city [18]

Third, further assumptions should be made related to the size of the tree, hence a tree of 20 inch-diameter was selected as an input for all trees to avoid assuming newly (small diameter) or very old grown trees (larger diameter). Lastly, the type of land use as per the National Tree Benefit Calculator tool should be selected from the following categories:
- Single family residential

- Multi-family residential

- Small commercial business

- Large business area

- Park or other vacant land

For this work, in order to simulate the urban plantation case where trees grow with minimum care and irrigation, the land use type selected was "Park or other vacant land".

\section{Results and Discussion}

Fig. 3 shows an estimate of the environmental benefits of planting the three urban trees in Qatar in terms of improving air quality and abatement of carbon dioxide. The figure indicates that these trees can improve air quality related to gaseous and particulate emissions. This can be achieved by:

- Absorbing pollutants like ozone, nitrogen dioxide and sulfur dioxide through leaves

- Intercepting particulate matter like dust, ash and smoke

- Releasing oxygen through photosynthesis

- Reducing energy use and subsequent pollutant emissions from power plants.

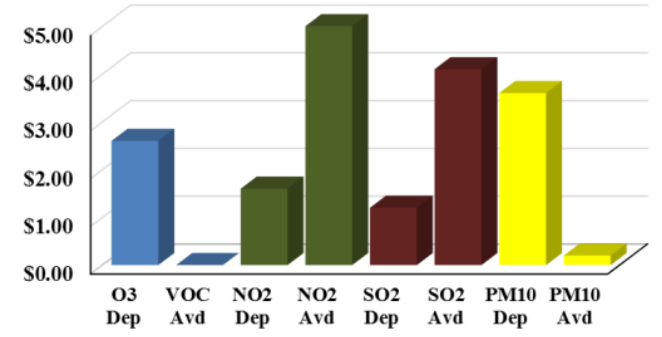

Acacia Dep Avd Dep Avd Dep Avd Dep Avd

Ziziphus

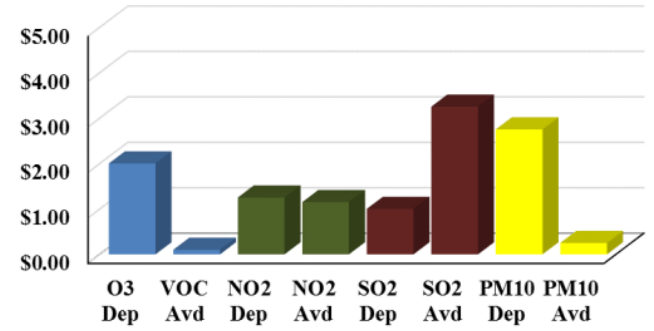

Palm Date

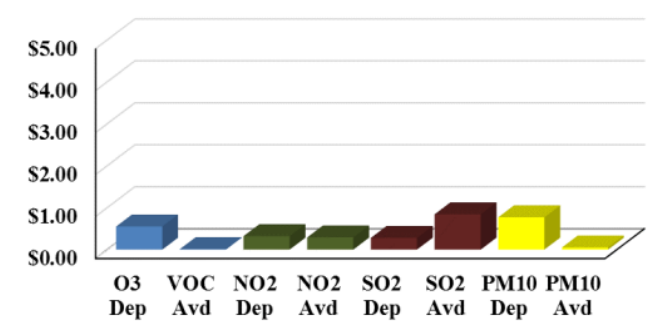

Fig. 3 Estimated benefits of different urban trees in Doha city in terms of air quality improvement, (Legend: Dep: deposited and Avd: Avoided)

The general trend of improved environmental benefits is shown to be the best when Acacia tree is planted and the least for palm date trees with approximate total value of $14.41 \$$ (Acacia) $>11.11$ (Ziziphus) $>2.97 \$$ (palm date). One general observation is noted as well that the three trees are not efficient to reduce/ remove volatile organic compounds (VOC) This is mainly due to the fact that trees emit VOC through their cells naturally as insect and animal attractants or repellents which play crucial role in the plant's defense and survival system $[8,13]$. On the other hand, amongst the gaseous pollutants, ozone is reduced to a great extent. This trend has been reported earlier by Schladitz et al. [19] and Nowak et al. [20] where they found that ozone removal by trees was the highest among all studied air pollutants. This significant removal of ozone is found to be related with the relatively high deposition velocities for ozone which is generally associated with high local ozone concentrations in the cities [13]. Moreover, sulfur dioxide takes another route by being absorbed into the plant tissues through the stomata. It then reacts with water on inner-leaf cell walls to form sulfurous and sulfuric acids. These acids further react with other compounds and be transported get different parts of the plant [21]. 
Trees are not only efficient to abate most gaseous pollutants as described earlier. In fact, they can be also efficient to reduce PM concentration in the air. Conceptually, trees can affect PM concentration in a three-step process. First, the incoming air flow carries a certain amount or concentration of PM which can be expressed in $\left(\mu \mathrm{g} / \mathrm{m}^{3}\right)$. Then, this incoming airflow passes through the canopy (the higher part of the plant above the ground) which removes part of the PM. Hence, in some occasions, part of the incoming air flow might be deflected leading to an increase of PM concentration locally upwind the tree. Third, the cleaner air (carrying less PM content) exits the canopy and continues moving downwind. This cleaner air mixes with other air over some distance that did not pass through the canopy which ends up having PM concentration that approaches the average concentration for that area (redilution).

More specifically, the reduction in PM concentration by each tree is achieved via the two following mechanisms: (i) an avoided fraction or by (ii) dry deposition process. Dry deposition is the mechanism by which vegetation removes air pollutant from the troposphere during a nonprecipitation period [13]. This mechanism depends on the nature of pollutant whether it is particulate or gaseous, having high or low density, diameter range, etc. It also depends on the nature and characteristics of the surfaces which include the chemical nature, roughness and size of those surfaces. The other critical factor is weather conditions such as ambient temperature, solar radiation, wind speed and direction, etc. [13]. Hence, when a pollutant accumulates on the surface of leaf tree, it can be removed either through leaf stomata absorbing gaseous pollutants or by the leaf intercepting particulate matter [22]. The first process causes the diffusion of pollutants into the inner part of leaves. These absorbed pollutants, in turn, may react with plant surfaces. In the second process, leaf surface intercepts PM leading to the reduction of PM concentration in the air through the wind action [22].

Moreover, trees play an important role in reducing carbon dioxide concentrations. Fig. 4 shows that the overall environmental benefit in reducing $\mathrm{CO}_{2}$ concentration follows the same trend of the findings displayed in Fig. 3 with Acacia tree to be the most efficient and the palm date tree showing the least removal values.

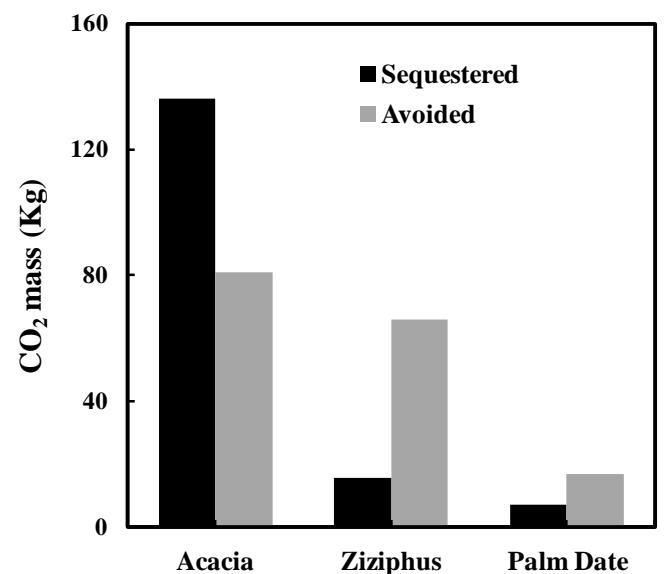

Fig. 4 Estimated benefits of different urban trees in the city of Doha in terms of carbon dioxide abatement

Trees mainly reduce $\mathrm{CO}_{2}$ concentration when they sequester carbon dioxide $\left(\mathrm{CO}_{2}\right)$ in their roots, trunks, stems and leaves during their growth period, and in wood products after they are harvested. One more indirect way of trees role in reducing $\mathrm{CO}_{2}$ is when trees are planted near buildings, they can reduce heating and air conditioning demands by acting as thermal shed and hence, reduce $\mathrm{CO}_{2}$ emissions associated with power production. Liu et al. [23] reported on the quantification of carbon storage and sequestration by urban forests in the city of Shenyang in China. For their estimation, the researchers used biomass equation utilizing several urban forest and field survey data derived from high resolution images. The results were reported in monetary values showing that forest areas within the third-ring road of Shenyang stored 337,000 tons of carbon which is equivalent to $\$ 13.88$ million. This value is estimated to have an impact of reducing the annual carbon emissions by $0.26 \%$ in Shenyang. The results showed as well that there was a variation of carbon storage and sequestration rate among different species types, age and composition within the urban forests studied. This has provided an insight for decision makers and public sector to better understand the role or urban forests and make better management plans for those areas [23].

The response of plants towards air is usually assessed by a factor that is referred to as an Air Pollution Tolerance Index (APTI) [21,24]. The APTI is used by researchers to select plant species tolerant to air pollution and it can be determined following the method of Singh et al. [25, 26]. The formula of APTI is given as:

$$
\mathrm{APTI}=[\mathrm{A}(\mathrm{T}+\mathrm{P})+\mathrm{R}] / 10
$$

where $\mathrm{A}=$ Ascorbic acid content $(\mathrm{mg} / \mathrm{g}), \mathrm{T}=$ total chlorophyll $(\mathrm{mg} / \mathrm{g}), \mathrm{P}=$ $\mathrm{pH}$ of leaf extract, and $\mathrm{R}=$ relative water content of leaf $(\%)$.

The order of the estimated environmental economic value of the three tree species as discussed above is found to be in good agreement with their APTI (Table 1). The higher the APTI, the more tolerant the tree is for air pollution, while lower values indicate sensitive species with lower air pollution abatement capacity.

Table 1 Air Pollution Tolerance Index of Acacia, Zizphus and palm date trees

\begin{tabular}{lll}
\hline Species & APTI & Reference \\
\hline Acacia & 30.0 & {$[27]$} \\
Ziziphus & 13.2 & {$[27]$} \\
Palm Date & 11.5 & {$[21]$} \\
\hline
\end{tabular}

\section{Conclusion}

By considering and investigating the services provided by trees for ecosystems, an optimized design and relevant economic decisions could be made towards the use of trees as a way to improve environmental quality, human health and the well-being for our modern societies. A fundamental factor to meet this goal is the data obtained on the impact of the urban forest structure (e.g. species composition) on air quality. In this work, we investigated the air quality impact of three abundant tree species under the city of Doha's environmental conditions, namely Acacia (Wattles), Ziziphus (Sidra) and Phoenix dactylifera (palm date) trees. We successfully evaluated their respective ability to abate gaseous and particulate pollutants through the use of the National Tree Benefit Calculator. Our results showed that the environmental benefits of urban trees in the city of Doha are gained by improving air quality and abatement of carbon dioxide concentration, in addition to be highly efficient to reduce $\mathrm{PM}$ concentration in the air. Moreover, the reduction of $\mathrm{CO}_{2}$ concentration was found to follow the same trend for the three species, with the particularity that Acacia tree was found to be the most efficient and presented the highest EEV in Doha. Hence, we conclude that, in order to have adequate, green infrastructure-based policies to mitigate air pollution in cities, urban planning that include vegetation should be implemented on larger scales. In addition, the policy-makers should necessarily consider the integration of efficient green infrastructure management, where possible trade-offs with other ecosystems services and urban sustainability goals are fully met.

\section{Author Contributions}

All the authors contributed to the analysis of data obtained and writing the article.

\section{Competing Financial Interests}

The authors declare no competing financial interests.

\section{References}

[1] S. Janhäll, Review on urban vegetation and particle air pollution - Deposition and dispersion, Atmos. Environ. 105 (2015) 130-137.

[2] S. Roy, J. Byrne, C. Pickering A systematic quantitative review of urban tree benefits, costs, and assessment methods across cities in different climatic zones, Urban For. Urban Green. 11 (2012) 351-363.

[3] D. Bell, M. Jayne, Small cities? Towards a research agenda, Int. J. Urban Reg. Res. 33 (2009) 683-699.

[4] X. Deng, Z. Li, J. Huang, Q. Shi, Y. Li, A revisit to the impacts of land use changes on the human wellbeing via altering the ecosystem provisioning services, Adv. Meteorol. 2013 (2013) 907367-1-8.

[5] X.Z. Deng, C.H. Zhao, H.M. Yan, Systematic modeling of impacts of land use and land cover changes on regional climate: A review, Adv. Meteorol. 2013 (2013) 317678-1-12.

[6] B. Aissa, R.J. Isaifan, A. Abdulla, V. Madhavan, Structural and physical properties of the desert-dust particles and their influence on the PV panels performance in Qatar, Sci. Rep. 6 (2016) 31467.

[7] R.J. Isaifan, A. Samara, W. Suwaileh, D. Johnson, W. Yiming, A.A. Abdallah, et al., Improved self-cleaning properties of an efficient and easy to scale up $\mathrm{TiO}_{2}$ thin films prepared by adsorptive self-assembly, Sci. Rep. 7 (2017) 9466.

[8] D.J. Nowak, The effects of urban trees on air quality, USDA Forest Service, Northeastern Research Station, Syracuse, NY, 2000. 
[9] W. Mell, S. Manzello, A. Maranghides, D. Buty, R. Rehm, The wildland urban interface fire problem- current approaches and research needs, Int. J. Urban Reg. Res. 19 (2010) 238-251.

[10] B. Maher, I. Ahmed, B. Davison, V. Karloukovski, R. Clarke, Impact of roadside tree lines on indoor concentrations of traffic derived particulate matter, Environ. Sci. Technol. 47 (2013) 13737-13744.

[11] L. Chen, C. Liu, L. Zhang, R. Zou, Z. Zhang, Variation in tree species ability to capture and retain airborne fine particulate matter (PM2.5), Sci. Rep. 7 (2017) 3206.

[12] J. Logan, Ozone in rural areas of the United States, J. Geophys. Res. 94 (1989) 8511-8532.

[13] W. Selmi, C. Weber, E. Rivière, N. Blond, L. Mehdi, D. Nowak, Air pollution removal by trees in public green spaces in Strasbourg city, France, Urban For. Urban Green. 17 (2016) 192-201.

[14] J.H. Amorim, J. Valente, P. Cascao, V. Rodrigues, C. Pimentel, A.I. Miranda, et al., Pedestrian exposure to air pollution in cities: modeling the effect of roadside trees, Adv. Meteorol. Adv. Meteorol. 2013 (2013) e964904- e964920.

[15] Internet Geography, World Climate Zone, 2015. http://www.geography.learnontheinternet.co.uk/topics/climatezones.html (Accessed on: 01.12.2017).

[16] J. Norton, S. Abdul Majid, D. Allan, M. Al Safran, B. Böer, R. Renee A. Richer, An illustrated checklist of the flora of Qatar, 2009. http://www.unesco.org/fileadmin/MULTIMEDIA/FIELD/Doha/pdf/SC/Plant $\% 2520$ Species\%2520Checklist\%2520of\%2520Qatar (Accessed on: 20.11.2017).

[17] Anonymous, Adaptation of Plants in Qatar, Environmental Stucies Center, Plant Life in Qatar, Doha, Qatar, 2015.
[18] E. Mousa, R. Bari, The flora of the state of Qatar: Its history and present-day status, Qatar Univ. Sci. J. 25 (2005) 113-118.

[19] A. Schladitz, T. Muller, A. Nowak, K. Kandler, K. Lieke, A. Massling et al., In situe aerosol characterization at Cape Verde Part 1: particle number size distribution, hygroscopic growth and state of mixing of the marine and Saharan dust aerosol, Tellus. 63B (2011) 531-548.

[20] D.J. Nowak, Urban tree effects on fine particulate matter and human health, Arborist News, April (2014) 64-67.

[21] A.A. Salih, A.A. Mohamed, A.A. Abahussain, F. Tashtoosh, Use of Some trees to mitigate air and soil pollution around oil refinery, Kingdom of Bahrain, J. Environ. Sci. Pollut. Res. 3 (2017) 167-170.

[22] D.J. Nowak, D.E. Crane, J.C. Stevens, Air pollution removal by urban trees and shrubs in the United States, Urban For. Urban Green. 4 (2006) 115-123.

[23] C. Liu, X. Li, Carbon storage and sequestration by urban forests in Shenyang China, Urban For. Urban Green. 11 (2012) 121-128.

[24] A. Gholami, A. Mojiri, H. Amini, Investigation of the air pollution tolerance index (APTI) using some plant species in Ahvaz region, J. Anim. Plant Sci. 26 (2016) $475-480$.

[25] H. Sjoman, A. Nielsen, Selecting trees for urban paved sites in Scandinavia- A review of information on stress tolerance and its relation to the requirements of tree planners, Urban For. Urban Green. 9 (2010) 281-293.

[26] S.K. Singh, D.N. Rao, M. Agrawal, J. Pandey, D. Narayan, Air pollution tolerance index of plants, J. Environ. Manage. 32 (1991) 45-55.

[27] S. Das, P. Prasad, Seasonal variation in air pollution tolerance indices and selection of plant species for industrial areas of rourkela, Indian J. Environ. Prot. 30 (2010) 978-988. 